\title{
Analyzing the Reasons Causing the Trend of Yaoi in Japan
}

\author{
Yue Liu
}

\author{
Shenzhen College of International Education, Shenzhen, Guangdong, China \\ 2242335424@qq.com
}

\begin{abstract}
Today, it is not uncommon to see Japanese women discussing romance between two men. Yaoi are works of male-male romance created by and for women. There are multiple reasons contributing to females' fervor in yaoi. This paper will first analyze micro and psychological factors. This paper finds that in yaoi, females can seek comforts due to its power balance and weakening of male characters to satisfy women's unequal experiences. Besides, females tend to idealize the male-male relationship as the perfect paradigm for a heterosexual model. Additionally, most women find yaoi as a medium to project sexual fantasies that cannot be satisfied in real life due to yaoi's creativity and less moral regulations. The broader context of the 1990s account for this phenomenon as well. The first reason is women's increasing desire to find true love and romance through yaoi. The second factor is the bursting of the bubble economy in early 1992 and its various impacts on female and younger male generation. Japan's traditional appreciation for Yūgen also contributes to Japanese' accepting attitude toward bishōnen and gender blurring in yaoi. Lastly, the Sexual Revolution and appearance of AIDS contribute to women's exploration of sexual desires in yaoi. The paper ends with an evaluation of yaoi's negative effects on women in general. Due to projections of female attributes to the submissive male character in a relationship, female stereotypes are continued through yaoi. Further, some yaoi fans are unduly submerged in it, isolating them from the real society. Finally, yaoi culture itself is still not accepted by the broader community and thus leading to abuses of yaoi fans.
\end{abstract}

Keywords: Yaoi, male homosexual love, June, June mono, androgyny, uke, seme, bubble economy, enjokōsai, Shitsurakuen genshō, bishōnen, Yügen, Sexual Revolution, AIDS.

\section{INTRODUCTION}

Comics, anime, and fanfictions of love between males made by and for women is presently a momentous phenomenon across the globe. This is particularly widespread in Japan. From a research by Kaneda and Miura, [1] about 150 BL (boy love narratives) yaoi manga comics and more than 30 BL yaoi manga magazines are published each month in Japan. Similarly, the yaoi market in Japan generates about 120 million yen annually. [2] In this sense, BL industry has already become a nonnegligible cultural part of Japanese society. There seems to be a special attachment that women feel towards male homosexual love.

Yaoi is defined as "the theme, the texts, and the (sub)genre of male-male romance, usually created by female artists/writers for female audiences." [3] The acronym of yaoi stands for 'yamanashi, ochinashi, iminashi', which means no climax, no ending, no meaning. Yaoi's literal meaning is self-deprecating. It used to symbolize narratives that only feature sex scenes, without any plot or development of emotion. [4] However, yaoi has developed to be different from its original meaning. Now, yaoi tends to emphasis romance and emotion. Instead of making the sex scenes the only component, the female participants have come to stress those scenes as a demonstration of the characters' sophisticated love. In fact, present day yaoi tends to portray sex scenes with fragments and implications, no longer directly illustrating the detailed behaviors. [5]

It is worth noting that most yaoi are idealistic, not realistic. For instance, those men that are considered as 'bears' rarely occur in Japanese yaoi. In addition, yaoi tends to ignore the 'disgusting' aspects of adult sexual experiences such as "body hair, developed guts and genitals, and periods and pregnancy." [6] This intentional ignorance signify the yaoi producers and consumers' overly idealized opinion of homosexual love. In fact, the 
exclusion of adults in yaoi extended to the stereotypical portrayal and role of adults. In most cases, adult males are illustrated as secondary characters to guide the younger protagonists. For instance, Orphe Zavi, an adult, from the famous yaoi Ai no Kusabi, only supervises the protagonist Iason Mink's gang but does not involve in the romantic love between the two younger protagonists. [7] In certain types of yaoi marked for rape, adults usually are the perverts, sexually harassing the protagonists.

Yaoi was popularized in the 1990s. During this period, the LGBTQ+ group was less accepted than the current days. Yet, yaoi still received immense popularity in Japan. For example, one famous yaoi magazine, June, had a circulation of between 80,000 and 100,000 in 1995 . [8] In the early 90s, about 75 percent of attendees at komiketto (ACG conventions) are female, circulating yaoi works. [9] Japanese women have an obvious attachment to yaoi already since this period. Hence, to answer why Japanese females are specially attracted to male-male romance, the factors contributing to this period's flourishing yaoi must be focused upon.

\section{HISTORY}

One has to learn about the history of yaoi in order to understand the factors contributing to its popularity. According to Akiko Mizoguchi, the history of yaoi can roughly be divided into three time periods. [10] The first time period is from 1961 to 1978 , which saw the birth of yaoi culture. In 1961, Mori Mari (1903-87) wrote the first yaoi novel: The Lovers' Forest. However, yaoi was not yet popular until the flourishing period of shojō manga (girls' comics) in the 1970s. Yaoi, then, gradually developed into a special genre within shōjō manga.

The second period ranges from 1978 to 1991. It saw the rapid development of yaoi into an individual branch of fandom. Following the boom of the 1970s, magazine producers witnessed the popularity of yaoi and established June, a yaoi-exclusive magazine, in 1978. June represents the professional sphere of yaoi. In fact, works published in June are known to have common attributes. These are referred to as the Tanbi mono, or June mono. In this trope, there always will be a young and good-looking couple that begins with a romantic relationship but ends with a tragedy. [4] In a way, this partly reflects the ideals of Greek tragedy. Additionally, the June mono established the stereotypical roles of seme (top / aggressor) and uke (bottom / submissive). The amateur sphere of yaoi, dojjinshi, or self-published magazines, developed in the 1970 s as well. It is worth noting that despite being developed among commoners, yaoi dojinshi still follows the June mono. [10]

The last period continues from 1991 until present. It represents the wide popularization and generalization of yaoi. The establishment of BE-BOY comics in 1992 marked the transforming moment. On one hand, it extends yaoi beyond magazines into comic stripes. On the other hand, it is the first direct breakaway from the June mono. Besides the typical tragedy structures of bishonen (young and good looking males) love, yaoi since then came to incorporate more diverse tropes. For instance, the characters increasingly featured middle-aged and muscular males. In addition, character roles such as jōsama sasoi uke (queen-like and active uke) and hetare seme (shy seme) emerged as well, representing a break from the stereotypes. [10]

\section{MICRO REASONS FOR WOMEN'S CONSUMPTION OF YAOI}

To begin with, women extract enjoyment from yaoi for several psychological reasons. To understand these micro factors and their contributions, Japanese females' historical oppressions must be comprehended.

\subsection{Females' dislike of heterosexual relationships}

Before investigating womens' methods of finding security in yaoi, the reasons for their dislike of heterosexual relationship must be understood. Continued long through history, Japanese females have suffered from gender prejudices and various forms of oppressions.

In 1999, the period of rapid yaoi development, 95 percent of high esteemed vocations such as business and politics were still occupied by men. [11] In multiple aspects, men have far better opportunities than women. For example, men are more likely to have promotion opportunities than women because companies are worried for excessive maternity leaves. Or, boys were still weighed more significant than girls in domestic households, and boys were more likely to receive higher education than girls.

In fact, in the 90s, Japanese females' behaviors were largely restricted to the private sphere. When their husbands go out to work and participate in public activities, Japanese wives were obliged to caress their children and do housework. Although female participation rate was about 40.593 percent in 1991, [12] once the females become pregnant, they are likely going to leave the labor force for most of their lives. The onerous duty of nurturing a child takes up most of women's attention, leaving them no time to gain education or work.

In addition, Japanese females suffered from moral inferiority. Shintoism, the main religion in Japan, emphasized women's impurity due to menstruation and reproduction. Only until 1872 were women officially allowed to visit any shrine. [13] Beside Shintoism, the Japanese society has imposed unreasonable demands on women. Onna Daigaku (The Great Learning for Women) was a 'lesson to all girls' published in 1733 by Kaibara 
Ekken. Although this work is notorious now for its misogynistic treatment of women as unemotional objects, it was widely regarded as a paradigm for women in the $18^{\text {th }}$ and $19^{\text {th }}$ century. The book claimed that women must have strict demarcation from males. Women cannot walk alone on the street, nor hand items to or from males. Females must wake up earliest in the morning and go to bed the latest in order to take care of all family business. It even states that wives must regard the parents of her husband as more significant than her own parents. Females' submission to their male counterparts, father, brother, and son, is also stressed. [14] This ingrained submission that continued from generations to generations contributes to Japanese women's dislike of heterosexual relationships.

Through these and other limitations on female behaviors, females would subconsciously feel inferiority to men, and thus uncomfortable about heterosexual relationship. Additionally, Japanese women are disillusioned of heterosexual love due to the latent introduction of love and romance into Japan. Partly derived from Confucius filial piety and the Bushido (the way of the samurai) emphasis on loyalty, Japanese women were expected to sacrifice themselves for the good of the family by remaining a reproduction 'object.' [15] Alike to customs of arranged marriages in Asian countries such as China and India, Japan is known for its extensiveness of arranged marriages, where sophisticated emotional connections between the couple are usually absent. Even today, about 5 percent to 6 percent Japanese still have their marriages organized by their parents. [16] As a result of this lack of ardor in marriage, Japanese females, either subconsciously or intentionally, find it difficult to find love passions in heterosexual relationship. As later will be mentioned, women's failure to seek comforts in heterosexual romance will turn them to rely on male homosexual romance for their unreceived love.

\subsection{Female comforts in yaoi}

The first theory for explaining females' interests in homosexual literature is the comfort that females can find in yaoi. Through yaoi, females can find their niche in the world.

In a male-male romantic relationship, there are relatively few involvements of females. As a result, females have placed themselves in the observer position. Through this alienated position, women can avoid the discomforts from heterosexual love. Already experiencing gender bias, women are unlikely going to spend time and money on heterosexual literature which further these prejudices. For example, most female protagonists in heterosexual literature own stereotypical roles. They are usually shy, submissive, and easy to molest. Moreover, these protagonists frequently have exaggerated body parts such as breasts and hips which are aimed to satisfy male readers. Consequently, most females are dissuaded by the presence of such female characters in heterosexual narratives. They are not looking for entertainments that harass their sexual identities. Thus, yaoi becomes a suitable entertainment for Japanese females. Due to the little presence of female, yaoi does not reflect misogynistic views. And since yaoi is created by and for women, female readers can build intimate connections with other females. For instance, most yaoi comic strips include "girly-girl" notes that introduce the comic producers as kawaii (lovable) figures and share gossips. [6]

In yaoi, females are also able to experience a power balance. In the real world, females have wielded much less power than their male counterparts. Most public and economic decisions are still made by the husbands in the family, while women can only decide on trivial household options. Although the Basic Law for a GenderEqual Society came into play in June 1999, its political promises are rarely achieved. [17] Hence, for the most span of the 1990s, Japan remained its traditional gender power imbalance. In yaoi, nevertheless, females can gain more power. As the producer of yaoi, females wield unlimited power over the male characters. They can decide their appearances, their experiences during intercourse, there physical pain, and even their mental eccentricities.

In extension, males are often weakened in yaoi works. Generally, both male protagonists are presented with a tender hearts, easily influenced by emotional tumults. This goes against the typical male characteristics. In fact, Japanese men are particularly expected to behave in a strong and firm fashion. Due to traditional emphasis on loyalty and adamancy in Bushido and samurai's contempt of infatuation, men are expected to be unmoved by 'sissi' emotions. Men are also taught to focus on hard work and job instead of the 'useless' sensibility at home. On a similar note, most yaoi still features romantic love between bishonen, which diverges from the common male image of muscularity, tall, and hairiness. By revealing men's fragile side in yaoi, women are subconsciously bringing men closer to them as equal beings. Moreover, females are more likely to feel sympathy and maternal love to these male characters. In contemporary Japan, women are usually sheltered by men due to stereotypical considering that women cannot live on their own. In the world of yaoi, females, as the omniscient observer, are able to protect male characters by manipulating the setting and the plots. Compassion satisfaction is the "pleasure and satisfying feeling that comes from helping others." [18] In this case, women derive compassion satisfaction from weakening and further helping their male characters.

Another simple reason is that women feel pure satisfaction when reading yaoi works. Some heterosexual literatures are also created for and by women. This genre 
contains less misogynistic contents and more of the romance that women looked for. However, this type of literature was not widely popularized. The reason is due to women's jealousy. The presence of female protagonists makes it easy for women to identify themselves with the protagonist. At the same time when female readers and producers relish the beatific romance, they also question their own situations and why they do not have similar romantic experiences. In contrast, in yaoi, women are largely neglected, which most likely elicited females' enjoyment and excluded their jealousy because females rarely view male protagonists as rivals. [15] Women's pleasure derived from yaoi is key to understand why women seek refuge in yaoi under the pressure of stagnant economy, patriarchy world, lack of love, and the threats of AIDS, which will be mentioned later.

\subsection{Females' idealized relationship}

Despite comforts, females also find the male homosexual relationship in yaoi as an idealized heterosexual relationship, and thus indulge themselves in this 'perfect' relationship.

In yaoi, most uke resemble stereotypical females in various ways. They usually are shorter than the seme, sentimental, long-legged, with big eyes, and submissive. [6] There are rarely muscular or 'bear' $u k e$ 's, but largely adolescent boys. By characterizing the uke in this fashion, women can idealize the yaoi relationships as a perfect romantic relationship between men and women. As mentioned before, the idea of romantic love arrived late in Japan. By the time women realized love as the basis for a happy marriage, the deep disillusions in heterosexual love have already been implemented. Beside this reason, there are other factors contributing to women's pursue of romance in homosexual relationships.

The first reason for female's attraction in yaoi as a projection of imagined love is the disregard of female's physical pains. Through yaoi, females are having a losing sense of their feminine identity and the corresponding bias that they suffered. [19] Male homosexual intercourse does not feature females' painful experiences. Women's afflictive experiences of menstruation, pregnancy, giving birth, and hymen rupture are not presented. In addition, many females remain conservative of the female physical experiences, considering them as impure or not mentionable in the public. Thus, by reading and producing yaoi, women can ignore the discomforts of female experiences in sexual intercourse.

Secondly, females likely have considered male homosexual relationships as the perfect and equal paradigm for heterosexual relationships. One of Sarah Schulman's interviewee illuminates this idea: "images of male homosexuality are the only picture we have of men loving someone as an equal, it's the kind of love we want to have." [20] The physical differences of the two sexes convinced most women that equal heterosexual love is not achievable. In yaoi, the two male protagonists are more equal. This notion corresponds with reality. RobertJay Green, a sophisticated scholar on same-sex couple, revealed that homosexual couples are more egalitarian. They share responsibilities in various dimensions such as household expenditure, social interactions, and childrearing. [21] Specifically, male homosexual relationships are generally less violent and more tender in yaoi. And by 'feminizing' the uke, females can imagine themselves enjoying this equal relationship.

Another reason is the presentation of true love in yaoi. The male protagonists in yaoi face societal objections; thus, females commend it a bold act for the male protagonists to challenge this social rule. Women admired the characters' deep love that even empowered them to face social obstacles. June mono's tragic structure adds on to the image of the devoting couples. [5] At the same time, most women believed that they themselves are not experiencing the desirable true love. Deriving from the cultural denomination of ie (household) as an economic unit, Japanese family was largely oriented by pragmatic but not romantic decisions. In fact, most women considered marriage as the female version of employment and labor. [22] Women, thus, were convinced that typical materialistic marriages do not provide them with true love. As a result, women projected the romantic fantasies onto male homosexuals.

Further, women have the freedom of sexual exploration in yaoi. Traditionally, women have been relegated to the submissive position. In yaoi, women can decide on their own whether to identify with the seme or the uke. [6] Women no longer have to suppress their curiosity to becoming the dominant figure in a relationship. In fact, this exploration is demonstrated through the different point of view (POV) in yaoi, especially manga. In some cases, the story is told from the perspective of the $u k e$, which allows the producers and readers to experience being that specific uke and engage in the relationship. In other cases, yaoi is presented through a third person point of view, where both the uke and the seme are equally exposed to the readers. Other yaoi are told from the perspective of the seme. The presence of these various POVs suggests women's explorations of different roles in a romance. With this freedom of navigation, women enjoy producing and reading yaoi.

\subsection{Means to project sexual fantasies}

Yaoi also attracts women by being a medium for women to project their sexual fantasies and desires, alike to how some men would do so in watching pornography and hentai (overly sexualized manga). 
Both men and women have sexual fantasies. It is common and reasonable to have them. However, men and women project sexual fantasies differently. According to Kelly Healer, men are highly visual in precepting sex while women are more emotional. [23] Consequently, most men project their sexual fantasies onto people that they are in touch with in real life. Further, they usually prefer real-life fantasies over unreal fantasies such as anime and manga. Women, nevertheless, appear more intrigued to the unreal fantasies such as male celebrities or imagined characters. Although this may be partly due to the deeply misogynistic presentations in pornography, women do have a tendency toward unrealistic fantasies.

Yaoi is a perfect medium for females' projection of sexual desires. Most of yaoi are narrated through writings, comics, or animes, not featuring actual figures. Due to this, there are unlimited imagination that women can produce through yaoi. For example, they can give the male characters animal characteristics, such as cat ears and dog tails. The yaoi can be set in another world, with magic and fantasy. In other cases, the common moral regulations do not apply. For example, one of the male protagonists may be dating two other protagonists at the same time. With all these freedoms allowed, females can project their unlimited sexual fantasies in yaoi, satisfying their sexual desires.

Beside the creativity allowed in yaoi, females feel less restricted morally. Although the LGBTQ+ movement was prevalent in the 1990 s, male homosexual couples were still rarely seen. That is to say, most women are not personally connected to male homosexual couples. As a result, love between men was seen more to be existing in fantasy rather than reality. Recognizing their alienations from the real homosexual community, women felt less restricted to create yaoi contents that are considered inappropriate. For instance, some yaoi features violence against the $u k e$ as part of the sexual intercourse. Other yaoi includes infidelity within a couple, and the controversial topic of surrogacy. Women also enjoy a more objective view of yaoi. [5] Women are less likely going to relate with the pains that male characters suffered due to unbecoming plots. Thus, women are likely attracted to the freedom of imagination in yaoi.

\section{MACRO REASONS FOR YAOI}

The reasons for women's special attraction to yaoi can be seen from a broader context, such as the contemporary economic conditions, global consciousness of sex, pandemic of sexually transmitted diseases, and Japan's historical and contemporary cultures.

\subsection{Japanese perception of love in the 1990s}

The contemporary Japanese notion of detachment of love and body and women's lack of love contribute to women's desperate refuge in yaoi.
In the early 90s, enjokōsai (a sexual transaction, or aid-date, between underage female students and middleaged men) [24] reached its peak. Most female high school students were known to engage in enjokōsai no matter their academic performances, family education, or any backgrounds. In the late 90s, the Shitsurakuen gensho (Paradise Lost phenomenon) also permeated the society. This phenomenon witnessed married individual's increasing reliance on extramarital affairs to satisfy their inner void from unemotional economic marriages. Both these phenomena indicate at the Japanese' prevalent notion of division between love and the body. This is the moral education that most Japanese, especially females, have received. [24]

For most of Japanese female in the 90s, the act of sexual intercourse is no longer tied with romantic love. [24] In fact, most women consider their body only as a commodity that can be sold to gain economic rewards. This is also evident in the thriving burusera (selling used school uniforms or underwear to fetishists) [25] shops. According to Hayami and Miyadai, the main reason for the enjokōsai and Shitsurakuen genshō phenomena is a lack of self-esteem, and thus a lack of love. During the height of post-war economic boom, Japanese fathers still retained the strict discipline of not giving in to emotions. This applies also to how they treat their daughters: with stoic manners and lack of care. On the other hand, mothers were more like friends to the daughters, spending time with them on shopping and cooking. However, this mother-daughter interaction does not provide the daughters with enough parental love. As a result, most Japanese females have developed to be diffident. [24] Then, many female high and middle school students endeavored to seek parental love from enjokōsai, where older men would usually provide them with good clothes and presents. [24] Similarly, married women rarely experience affectionate love in their marriages so they tried to find love through engaging in extramarital affairs.

At the same period, yaoi flourished. Although sexual intercourse is an indispensable part of yaoi, its main function is to demonstrate the male protagonists' deep affections that they are willing to perform this behavior. In yaoi, love is tied closely to the body. By going against the societal customs of intercourse as an unemotional behavior, yaoi expresses women's yearnings for true love. Since this particular emotion is rarely found in the impersonal enjokōsai or Shitsurakuen genshō, women turned to find the presence of caring love in yaoi.

\subsection{The bubble economy}

Following the bursting of Japan's bubble economy in early 1992, the traditional male images began to change. Previously, Japanese men are presented as powerful and diligent figures, practicing the loyal spirit of Bushido to their companies. However, since the beginning of the Lost Decade (period of Japanese economic stagnation 
roughly from 1992 to 2002), unemployment skyrocketed. In 1991, the unemployment rate was $2.1 \%$. In 2002, this figure surged to $5.5 \%$. [26] As a result of this widespread unemployment, women's perceptions on family and men have changed to promote a renewed interest in yaoi.

Women also suffered from the Lost Decade. Still considered as inferior workers to men, women experienced unemployment and reduced wages on a broader scale. For example, from 1991 to 1994, percentage of female employment in industry had dropped from 27.7 to 25.82. [27] Similarly, percentage of females in the labor force decreased from 40.593 in 1991 to 40.297 in 1993. [12] Experiencing unemployment and thus lower standards of living, women looked for a medium to escape the painful reality.

Furthermore, the Lost Decade had shattered the prevalent harmonious family image in Japan. Prior to the bursting of the bubble economy, the presence of 'lifelong employment' in companies made companies seem like embracing families for all its employees. The employers are like the parents, while the employees are the children who work to enjoy the benefits, such as healthcare, residency, and insurances. After the economic stagnation, these so-called family - companies - began to fire its employees. Then on, most Japanese were disillusioned of the family deceit. The idea of a shattered family was also brought into the private sphere. The superficial family happiness seemed like a delusion that will also fade away. Disheartened by this idea, men and women looked to navigate other forms of relationships that can provide them with stability and happiness.

Due to women's dearth for a spiritual support and love relationship beyond traditional family, women looked to male homosexual love as an ultimate relationship that can provide them with comfort. The reason is tied to the new generation's male images. Due to the economic stagnation, many previous male jobholders lost their jobs while the young labor force could not find jobs. Unable to sustain themselves with economic basis, the younger male population could not fulfill the traditional expectations of devoting and strong employees. Instead of struggling to get jobs based on hard work, most of these men became hikikomori (people who refuse to leave their home) [28] or men that lack traditional male strengths. As a result of this new male social group, many women were convinced that these men are weak and thus less dependable. In fact, women considered this weakness as similar to the stereotypical view of females' submissiveness in relationship. Considering this new male community as a suitable candidate for $u k e$, women began to incorporate this weak male figure into yaoi and wield freely their imaginations.

\subsection{Japanese aesthetics: androgyny}

Japan is known for its unique aesthetics. This special taste has extended to the field of gender and led Japanese women to easily accept male homosexual love in yaoi.

Why was yaoi most prevalent in Japan but not in other countries? This can be derived back to Japanese traditional aesthetics. Yügen, the idea of irregularity and ambivalence, can be found throughout Japanese culture. For instance, Japanese buildings rarely appear in regularity and stoic fashion. Instead, they feature designs that seem 'out of place.' This emphasis on irregularity and vagueness is key to Japanese aesthetics. [29] Yügen also applies to gender and sexuality, where people without clearly defined genders are seen as beautiful in their pure forms.

Japan is also famous for its praise of androgyny. During the Tokugawa period, most samurai considered having sexual intercourse with women as inferior. Instead, they pursue sexual intercourse with bishonen and thought this as the true demonstration of male strength. In a way, this idea resembles that of ancient Greek and Roman, where sexual identity depends on activeness and passiveness, not heterosexual or homosexual. [30] Although not universal, male homosexual love is already common in Japan. For the Japanese, bishōnen were seen as embracing both male and female attributes, making them an identity similar to the $3^{\text {rd }}$ sex. This idea appealed to the Japanese. Bishonens became the embodiment of Yügen due to their elusiveness, purity, and transient beauty. [11] With this admiration of bishonen, the Japanese society, including women, is already more receptive towards male homosexual romance.

The idea of androgyny and gender blurring is also enhanced through kabuki (traditional Japanese popular drama performed with highly stylized singing and dancing). [31] Since women were banned from performing in the mid-seventeen centuries, many young and good-looking males took on to play the role of female characters. These males are known as the onnagata. Onnagata was highly popular in Japan. Bisexual male audiences were attracted by their beauty, while females learned how to be women form these onnagata. [11] It is obvious that both Japanese women and men were exposed to the androgyny and gender blurring for a long history, resulting in their subconscious acceptance of bishōnen. As a result, Japanese women are more accepting towards the prevalent presence of these bishōnen uke and seme in yaoi, contributing to yaoi's popularity.

\subsection{Global conditions}

The global context in the 1990s also should be considered. Particularly, the Sexual Revolution and the 
advent of AIDS contributed to women's reliance in yaoi to release sexual desires.

The Sexual Revolution that occurred between 1960s and 1980s saw the liberation of taboos on sexual intercourse and objections to sexual minorities such as the LGBTQ+ community. The leading members are Freudian Marxists, including Wilhelm Reich who promoted sexual desires as a natural impulse but which is suppressed by the society and thus needs to be liberated. At the same time, feminists advocated for women to accept their satisfactions from sexual intercourse and cease to consider this behavior as sinful. [30] Japanese women, too, were impacted by this movement. They began to explore gratifications from sex by publicizing their sexual fantasies and creating sex toys for women. The acceptance of sex opened Japanese women's interests in sexual contents, directly contributing to Japanese women's fervor in yaoi, where intercourse is still an indispensable content at that time. In addition, the Sexual Revolution's promotion of LGBTQ+ rights normalized Japanese women's attentiveness in male homosexual relationships, making yaoi more approachable to females. However, at this stage Japanese women had not yet became passionately engaged in yaoi.

The Sexual Revolution was a success in detaching the ideas of sexual intercourse and sins. However, the emergence of AIDS (Acquired Immunodeficiency Syndrome) in 1981 brought the global community back to the espouse where sex is a misdemeanor. The sexually transmitted virus frightened the world and associated sexual intercourse again with disease and impurity. In this case, Japanese women also feared the consequences of sex. For example, manga series such as Tomoi attempted to educate AIDS appeared [8] In this epoch, sex is avoided as much as possible. Nevertheless, after the Sexual Revolution, Japanese women were unable to simply stay away from sexual desires. Together with the miseries due to the bursting of the bubble economy, Japanese women looked to yaoi to escape reality and as a source of sexual fantasies.

\section{ADVERSE EFFECTS OF YAOI}

Despite the prevalence and popularity of yaoi, there are three main adverse effects of yaoi on female consumers and producers.

The first influence is the continuation of female stereotypes. As mentioned before, most uke in yaoi feature feminine attributes. This connection of submission and femininity reflects the yaoi participants' unchanged subconscious recognition of females' compliant role in a sexual relationship. In a sense, what underlies the homosexual relationships portrayed in yaoi is still a stereotypical heterosexual relationship. If this portrayal is to continue, future yaoi participants will continue to have similar views of female, unable to liberate stereotypical views on women.

The other drawback of yaoi is some women's overindulgence in it. Since yaoi is a method for Japanese women to escape reality, most characters are constructed into perfect beings. That is, they do not have any negative attributes such as laziness or a bad breath. The characters only have enchanting characteristics such as tall heights, handsome appearances, and optimistic attitudes. These characters fascinate the female readers, and often the female producers themselves are totally captured in this fantasy. As a result, yaoi participants may develop an excessively idealized standard when evaluating other people. They will impose the strict criterion of yaoi characters onto real people, who rarely are able to meet the standards. Then, these women may be disillusioned of the reality and engage in more sexual fantasies through yaoi. This vicious cycle will always continue, and those females who immersed themselves too deeply into yaoi will fail to connect to the society.

Lastly, yaoi continues to be a label that cannot be easily accepted. Seeing that women engage excitingly in the pornography of two men is likely going to be seen as strange to non-yaoi fans. This has always been the case. According to one interview of Sarah, a big fan of yaoi, she has experienced prejudice in class only because she wore a yaoi fandom T-shirt. People eyed her with horror and thought of her as a "pervert." After this occasion, Sarah never outwardly exposed herself as a yaoi fan anymore, and even condemned herself for participating in yaoi . [5] Beyond Japan, yaoi also had received social biases and criticisms from countries all around the world due to different cultural values on sexuality. Sarah's disheartening experience and the global prejudice is not uncommon. Without approaches to solve this, the bias will likely persist to be a problem in the future.

\section{CONCLUSION}

To sum up, both micro and broader macro reasons explain Japanese women's fervor for yaoi. Suffering from the historical misogynistic oppressions in the patriarchic society, Japanese women find it unfavorable to observe similar treatments in heterosexual literatures, where women are stereotypically portrayed as submissive and objects of their male partners. Consequently, these women relied on yaoi for entertainments. The power balance between two genders, weakened male character, and absence of uncomfortable female treatments intrigued females to consider yaoi as a safe space. Additionally, women look to the male homosexual relationships in yaoi as an idealized heterosexual love model due to their egalitarianism, opportunities for women's sexual exploration, and the presence of true love. Besides, women also find yaoi as a medium to allow their sexual imaginations due to creative medias and reduced moral restrictions. 
In the 1990s, the widespread situation of enjokōsai and Shitsurakuen genshō explain contemporary women's desires for love and their consequent pursuits of this emotion in yaoi. Simultaneously, the bursting of the bubble economy in early 1992 changed women's perceptions on gender and sexuality due to the shattered image of strong men and harmonious family. Japanese traditional aesthetic also comes into play by popularizing the notion of bishōnen and androgyny. Lastly, the Sexual Revolution play a vital role in enlightening Japanese women's view on sex while the arrival of AIDS forced these women to find a new platform for sexual desires.

Nevertheless, the yaoi phenomenon also has some negative influences. It continues the stereotypical opinion on sexual relationships, where men are aggressive and women are submissive. Furthermore, some women may have overreliance on yaoi, detaching them from the real society. Moreover, yaoi culture continues to suffer from prejudices, causing its participants stress and anxieties.

This paper illuminates how social phenomenon emerges due to the presence of multiple factors. All of the analyzed reasons have contributed partly to the popularity of yaoi today. From analyzing all of the causes, an interesting finding is that female oppressions have the highest significance in fueling yaoi. For instance, if women were not alienated from heterosexual literature due to its sexist content, women may not rely on yaoi for sexual fantasies or finding comfort. Or, if women are not in the submissive position in sexual intercourse, they will not identify the uke with femininity and further the stereotypical views of women. In whole, the extensive influence of gender oppression is alerting. If the results of gender oppression have even infiltrated women's entertainment created by themselves, gender oppression must have had other greater impacts that cannot easily be solved.

Beside the reasons causing the yaoi culture, its influence is also a major field that can be analyzed further on. Other than some of yaoi's negative effects that this paper briefly touches upon, there are other positive influences such as yaoi as a medium to build connection with the global environment and its economic significance. Moreover, comparisons on the different developments of yaoi in China and Japan can be analyzed based on the different cultures and how they each contribute to the differences. Both government's responses to yaoi can also be researched to gain insights into the implications of different government structures. Another comparison that can be made is with males' interest in female homosexual love and why this phenomenon did not become as popular as that of yaoi. Some possible reasons include the absence of misandry and thus lack of reason for men to seek comforts in female homosexual relationships.

The paper also has some limitations to its claims. Particularly, there are no specific evidence (such as data, census, or legitimate theory) to support the relationship between the analyzed factors and women's love for male homosexual romance. In fact, it is likely the case that every yaoi participant engage in yaoi due to some of the factors considered in this paper, but not the influence of all the factors together. For example, some women may experience minimal misogynistic treatments but still be attracted to yaoi due to a particular favor for bishonen. To this end, further research on evidence for these theories' applications to yaoi should be made.

\section{REFERENCES}

[1]. Junko, Kaneda, and Shion Miura. Seme X Uke' No Mekuru Meku Sekai: Dansei Shintai No Miryoku Wo Motomete. 2007.

[2]. Sugiura, Yumiko. Fujoshika Suru Sekai. Higashi Ikebukuro No Otaku Joshitachi. Tokyo: Chūōkōron shinsha.

[3]. Aoyama, Tomoko. "BL (Boys' Love) Literacy: Subversion, Resuscitation, and Transformation of the (Father's) Text." U.S.-Japan Women's Journal, no. 43 (2012): pp. 66.

[4]. Pagliassotti, Dru, Kazumi Nagaike, and Mark McHarry. Editorial: Boys' Love manga special section, Journal of Graphic Novels and Comics.

[5]. O'Brien, Amy Ann. Boys' Love and Female Friendships: The Subculture of Yaoi as a Social Bond between Women. 2008.

[6]. Camper, Cathy. "Essay: 'Yaoi' 101: Girls Love 'Boys' Love."' The Women's Review of Books, vol. 23, no. 3 (2006): pp. 24-26.

[7]. Yoshihara, Rieko and Katsumi Michihara, "Ai no Kusabi.” Koufuusha Shuppan (1990)

[8]. Shodt, Frederik. Dreamland Japan: Writings on Modern Manga. Berkeley: Stone Bridge Press, 1996.

[9]. Kinsella, Sharon. "Subculture in the 1990s: Otaku and the Amateur Manga Movement." Journal of Japanese Studies Vol. 24, Issue no. 2 (1998), pp. 289 $-316$.

[10]. Mizoguchi, Akiko. Male-Male Romance by and for Women in Japan: A History and the Subgenres of 'Yaoi' Fictions. 2003.

[11]. G. Henshall, Kenneth. Dimensions of Japanese Society: Gender, Margins and Mainstream. 1999.

[12]. "Labor force, female (\% of Total Labor Force) Japan." The World Bank. June 15, 2021. https://data.worldbank.org/indicator/SL.TLF.TOTL .FE.ZS?locations=JP\&view=chart.

(Accessed 
[13]. "Women in Shinto." WikiVisually. wikivisually.com/wiki/Women_in_Shinto. (Accessed July 29, 2021).

[14]. Ekken, Kaibara. "Onna Daigaku." in Sources of the Japanese Tradition, vol.2 (1958): pp. $222-231$.

[15]. McLelland, Mark. "Why Are Japanese Girls' Comics full of Boys Bonking?" Intensities: Jornal of Cult Media (2001): pp. 6.

[16]. "What's Omiai? - Japan's Take On Arranged Marriages." Japan Info. September 24, 2020. https://jpninfo.com/36254. (Accessed July 29, 2021).

[17]. Mari, Osawa. "Government Approaches to Gender Equality in the mid-1990s." Social Science Japan journal Vol. 3, No. 1 (2000): pp. 5.

[18]. "Compassion Satisfaction and Compassion Fatigue: Helpful tips for our Frontline Workers.” Psychiatry and Behavioral Sciences, October 29, 2020. https://med.uth.edu/psychiatry/2020/10/29/compass ion-satisfaction-and-compassion-fatigue-helpfultips-for-our-frontline-workers/. (Accessed July 30, 2021).

[19]. Otomo, Rio. "Politics of Utopia: Fantasy, Pornography and Boys Love." in Boys' Love Manga in Japan: History, Culture, Community, edited by Mark McLelland, Kazumi Nagaike, Katsuhiko Suganuma, and James Welker, pp. 5. Jackson, MS: University Press of Mississippi, 2015.

[20]. Schulman, Sarah. My American history: Lesbian and Gay Life During the Reagan and Bush Years. London: Cassell, 1994.

[21]. Green, Robert-Jay. "Same-Sex Couples May Have More Egalitarian Relationships." interview by Lourdes Garcia-Navarro. NPR, December 29, 2014.

[22]. Nakane, Chie. Japanese Society. Berkeley and Los Angeles: University of California Press, 1970.

[23]. Healer, Kelly. "Sexual Fantasy - Male and Female Differences." YouTube, July 23, 2010. https://www.youtube.com/watch?v=t3s22eMERcs. (Accessed August 1, 2021).

[24]. Ryang, Sonia. Love in Modern Japan. 2006.

[25]. Suzuki, Tadashi, and Joel Best. "The Emergence of Trendsetters for Fashions and Fads: Kogaru in 1990s Japan." The Sociological Quarterly, vol. 44, no. 1 (2003): pp. $61-79$.

[26]. Agnese, Pablo and Sala Hector, Unemployment in Japan: A look at the 'lost decade'. 2008.

[27]. "Employment in industry, female (\% of female employment) (modeled ILO estimate) - Japan.” The
World Bank, January 29, 2021. https://data.worldbank.org/indicator/SL.IND.EMPL .FE.ZS?locations=JP\&view $=$ chart. $\quad$ (Accessed August 1, 2021).

[28]. Cheng, Jennifer S. "Hikikomori: Salt Constellations." Agni, no. 81 (2015): pp. 104.

[29]. Keene, Donald. Appreciations of Japanese Culture. 1971.

[30]. Mottier, Veronique. Sexuality: A Very Short Introduction. 2008.

[31]. "Kabuki." Merriam-Webster. https://www.merriamwebster.com/dictionary/Kabuki. (Accessed August 1, 2021) 